Reprod. Nutr. Dévelop., 1986, 26 (1 B), 303-304.

\title{
La modélisation des cinétiques de dégradation des constituants pariétaux des aliments dans le rumen
}

D. SAUVANT, Michelle DORLEANS, Catherine DELACOUR, D. BERTRAND $(*)$, Sylvie GIGER

Station de Nutrition et Alimentation, I.N.R.A., Institut National Agronomique Paris-Grignon, 16, rue Claude-Bernard, 75231 Paris Cedex 05.

(*) I.N.R.A., Domaine de la Géraudière, 44000 Nantes.

Summary. In sacco degradability of cell wall (CW) was measured on 24 various concentrates and by-products. The potentially degradable $\mathrm{CW}$ disappeared according to a first-order process. However, CW degradation generally occurred after a lag phase. CW degradability was largely affected when particulate turnover was taken into account.

Ce travail a pour objet d'étudier les cinétiques de dégradation ruminale des constituants pariétaux des aliments. Différentes équations d'ajustement ont déjà été proposées (Waldo et al., 1972 ; Mertens, 1973 ; Mahlooji et al., 1984).

Matériel et méthodes. 24 aliments (tabl. 1) ont été choisis de manière à représenter un large échantillon de teneurs et de composition de la paroi végétale. Les teneurs en cellulose brute, NDF, ADF et ADlignine de ces aliments sont respectivement comprises entre 4,2-54,1, 16,9-82,3, 4,2-57,7 et $0,2-23,7 \%$ de la matière sèche (MS). La digestibilité in sacco (Gueneau et Bertrand, 1984) est mesurée sur des chèvres recevant du foin de luzerne ad libitum complémenté par $400 \mathrm{~g}$ d'aliment concentré. Les variations de la dégradabilité in sacco de la M. S. selon la durée d'incubation $(6,12,24$ et 48 h) et leur prévision ont été publiées (Sauvant, Bertrand et Giger, 1985).

Résultats et discussion. Les parois se dégradent selon un processus qui est décrit par deux modèles différents. Pour 7 des 24 aliments considérés (tabl. 1), le modèle est du type : PVNDt $=$ PVI + PVD. $e^{-k t}$, avec PVNDt : parois non dégradées après un temps $t$; $P V I$ : parois potentiellement indégradables ; PVD : parois potentiellement dégradables ; $k$ : taux de dégradation horaire de la fraction PVD. Les écarts-types résiduels (ETR) des ajustements sont compris entre 0,01 et 1,4\%. Pour les autres aliments, il est possible de réduire significativement la valeur de I'ETR en prenant en compte un temps de latence décrit par Mertens (1973), mais non testé sur des résultats expérimentaux : PVNDt $=$ PVI + PVD.e $e^{-k\left(1-e^{-h t}\right) t}$.

La fraction PVD est comprise entre 8,9 et $64,4 \%$ de la MS et la fraction PVI entre 1,5 et $69,0 \%$. Elles sont plus liées à la dégradabilité potentielle de la paroi (DP = PVD/NDF) qu'à sa teneur dans les aliments. Les valeurs de la dégradabilité potentielle de la paroi discriminent les aliments en 2 groupes : ceux à "paroi digestible " (tabl. 1 : 80,0 < DP $<91,2 \%$ ) et les autres $(38,2<\mathrm{DP}<64,4 \%$ ), les coques de tournesol se détachant nettement de ce groupe (DP $=12,3 \%$ ).

Le taux de dégradation horaire de la fraction PVD est en moyenne de $0,107 \mathrm{~h}^{-1}$ avec des extrêmes de 0,025 et $0,179 \mathrm{~h}^{-1}$. Pour les aliments à « paroi digestible " une relation significative et inverse associe le taux de dégradation en début d'incubation et leur teneur en NDF. Le taux de dégradation horaire $(\% h)$ calculé après $3 \mathrm{~h}$ d'incubation (TD 3) est largement expliqué par les teneurs en 
NDF (\% de la MS) :

$$
\text { TD3 }=5,60-0,061 \text { NDF } \quad(n=9 ; R=0,93 \text { ) }
$$

La phase de latence augmente donc avec la teneur en paroi de ces aliments.

En admettant un renouvellement horaire des particules de $0,05 \mathrm{~h}^{-1}$ le coefficient de dégradabilité de la paroi diminue sensiblement ( $\leq 57 \%$ ) et la fraction PVD dégradée (PVD 0,05) est comprise entre 4,2 et $31,4 \% \mathrm{MS}$. Elle est très liée à la fraction PVD; cependant la différence (PVD-PVD 0,05) s'accroît de façon plus que proportionnelle en fonction de la teneur en PVD :

$$
\text { (PVD-PVD 0,05) }=0,202 \text { (PVD) } 1,22 \quad \text { (n }=24 ; R=0,91 \text { ). }
$$

Cette relation montre que le transit des particules affecte plus la dégradation ruminale des aliments les plus riches en paroi digestible.

\begin{tabular}{|c|c|c|c|c|c|}
\hline \multirow[b]{2}{*}{ Aliment } & \multirow{2}{*}{$\begin{array}{c}\text { Dégradabilité } \\
\text { in sacco } \\
\text { de la MS } \\
\text { en } 48 \mathrm{~h} \\
(\%)\end{array}$} & \multicolumn{3}{|c|}{ Fraction NDF } & \multirow{2}{*}{$\begin{array}{c}\text { Dégradation } \\
\text { horaire K } \\
\text { de la fraction } \\
\text { PVD } \\
h-1\end{array}$} \\
\hline & & $\begin{array}{c}\text { non } \\
\text { dégradable } \\
\text { (PV| \% MS) }\end{array}$ & $\begin{array}{c}\text { dégradable } \\
\text { (PVD \% MS) }\end{array}$ & $\begin{array}{c}\text { dégradée } \\
\text { (PVD 0,05 } \\
\% \text { MS }\end{array}$ & \\
\hline T. de soja $(1)$ & 97,1 & 1,5 & 15,4 & 9,1 & 0,085 \\
\hline Pulpe d'agrumes (1) & 95,8 & 2,5 & 19,9 & 12,8 & 0,143 \\
\hline Graine de lupin (1) & 95,4 & 4,4 & 21,3 & 13,4 & 0,146 \\
\hline Mélange $C(2)$ & 90,7 & 9,2 & 8,9 & 5,4 & 0,200 \\
\hline Orge (5) & 89,1 & 10,0 & 12,6 & 8,6 & 0,109 \\
\hline T. d'arachide (5) & 87,8 & 11,4 & 17,0 & 13,0 & 0,168 \\
\hline Avoine (5) & 81,4 & 16,2 & 12,6 & 4,2 & 0,025 \\
\hline T. de colza & 80,0 & 16,5 & 18,2 & 10,9 & 0,132 \\
\hline Son $(5)$ & 79,3 & 20,3 & 32,2 & 21,3 & 0,089 \\
\hline Mélange $P$ (3) (5) & 76,8 & 19,6 & 22,2 & 13,4 & 0,076 \\
\hline T. de tournesol & 74,0 & 24,9 & 15,4 & 9,6 & 0,179 \\
\hline Coques de soja (1) & 93,1 & 6,3 & 51,4 & 24,3 & 0,149 \\
\hline Mélange PR $\left({ }^{1}\right)\left({ }^{4}\right)$ & 92,6 & 5,1 & 33,4 & 19,1 & 0,094 \\
\hline Pulpe de betteraves (1) & 92,5 & 6,6 & 47,2 & 26,1 & 0,094 \\
\hline$T$. germe de maïs $\left({ }^{1}\right)$ & 88,6 & 5,1 & 50,7 & 24,4 & 0,055 \\
\hline T. Coprah (1) & 83,5 & 15,2 & 56,7 & 31,4 & 0,150 \\
\hline T. palmiste (1) & 78,4 & 14,7 & 64,4 & 20,9 & 0,092 \\
\hline Luzerne déshydratée & 69,3 & 26,9 & 27,7 & 16,1 & 0,118 \\
\hline Foin de luzerne & 68,5 & 26,7 & 23,7 & 15,7 & 0,120 \\
\hline Drèches de brasserie (5) & 64,9 & 20,9 & 37,8 & 19,0 & 0,051 \\
\hline Coques de cacao & 59,8 & 31,5 & 20,6 & 11,4 & 0,108 \\
\hline Pulpe de raisin (5) & 49,0 & 37,5 & 26,6 & 12,8 & 0,047 \\
\hline Paille d'avoine & 47,8 & 33,9 & 48,4 & 16,3 & 0,036 \\
\hline Coques de tournesol & 27,0 & 69,0 & 9,7 & 5,2 & 0,151 \\
\hline
\end{tabular}

TABL. 1. - Principales caractéristiques des aliments étudiés.

(1) Aliment à « paroi digestible ». (2) Orge (30\%), blé $(20 \%)$, son (15\%), avoine (10\%), t. de soja $(10 \%)$, t. d'arachide $(5 \%)$, mélasse $(6 \%)$. (3) Luzerne déshydratée $(30 \%)$, son $(30 \%)$, pulpe de raisin $(10 \%)$, t. de tournesol $(10 \%)$, t. de soja $(10 \%)$, mélasse $(10 \%)$, \{4) Pulpe de betterave $(30 \%)$, coques de soja (20\% pulpe d'agrume $(10 \%)$, t. germe de maïs $(10 \%)$, t. de soja (10\%), lupin (10\%), mélasse $(6 \%)$. (5) Aliments dont la cinétique de dégradation est décrite par le modèle sans temps de latence.

Gueneau S., Bertrand D., 1984. Cahier des techniques de I'.N.R.A., 4, 33-38.

Mahlooji M., Ellis W. C., Matis J. H., Pond K. R., 1984. Can. J. anim. Sci., 64, 114-115.

Mertens D. R., 1973. Application of theoretical mathematical models to cell wall digestion and forage intake in ruminants. Ph. D. Thesis, Cornell Univ. Ithaca, N.-Y.

Sauvant D., Bertrand D., Giger S., 1985. Anim. Fd. Sci. Techn. (sous presse).

Waldo D. R., Smith L. W., Cox E. L., 1972. J. Dairy Sci., 55, 125-131. 